\title{
Dialogue with Conflict: Education and Conflict Coping in Israel ${ }^{1}$
}

\author{
Anders Høg Hansen
}

This article addresses educational encounter projects between Jewish and Palestinian Arab high school students, teachers and facilitators in the state of Israel after the outbreak of the intifada (year 2000). Through the display of ethnographic footage and commentary from particular workshops in a high school encounter program, some of the key obstacles to dialogic engagement, the problems of and potentials of narrative reconfiguration and the limitations of the intergroup approach are illustrated. The particular educational model is practised, with variations, at some of Israel's major and pioneering institutions for peace and conflict education. The workshops under scrutiny in this article were taking place at Givat Haviva - a centre for peace and conflict related educational and cultural programs, including language and art courses.

\section{Introduction}

This article addresses educational encounter projects between Jewish and Palestinian $\mathrm{Arab}^{2}$ high school students, teachers and facilitators in the state of Israel during the present intifada. The particular type of project under scrutiny in the article is a model, with variations, taking place at some of Israel's major and pioneering institutions for peace and conflict education. The workshops at Givat Haviva - a centre for peace and conflict-related educational and cultural programs, including language and art courses - will be presented here.

The purpose of the article is to illustrate - through the display of ethnographic footage and commentary-some of the key obstacles to dialogic engagement (Bakhtin, 1981), the problems of and potentials of narrative reconfiguration (Ricoeur, 1983, 1996) in projects adopting the intergroup approach, one of the dominating paradigms in the conflict education industry in Israel (Hewstone \& Brown, 1986; Halabi \& Beck-Phillips, 2001; Halabi \& Sonnenschein, 2004).

\footnotetext{
Anders Høg Hansen is a lecturer at School of Arts and Communication, Malmö University. He finished his PhD in cultural studies at Theory, Culture \& Society Centre, Nottingham Trent University in November 2003, and may be contacted at Malmö University, School of Arts and Communication, Att. Anders Høg Hansen, Se 205-06 Malmö, Sweden. Tel. 004529827441 / 00453583 2821. Email: anders.hog-hansen@k3.mah.se
} 


\section{Blind Ethnography?}

The focus of the field work in 2001 was on the non-verbal aspects of the encounter: the students' and facilitators' behaviours, their body language, gestures, attitudes, their ways of showing solidarity and antipathy, their patterns of attack, defence and accommodation in embodied and unhabitual space. Only in a secondary and informal way was the analysis of the actual dialogues centre of the attention. A language barrier made this impossible (I know written Arabic and only bits of oral Hebrew/Arabic). In one sense I then became a 'blind' ethnographer, but in another sense a more seeing one, since languages other than the spoken could more easily take the forefront. This written representation of the experience nevertheless tries to catch up on the linguistic deficit by bringing in comments and summaries of the actual dialogues from talks with facilitators, teachers and students, which happened either informally between talks, through translation into English, or through formal interviews with facilitators at other times.

The voices in this article work as a two-fold representation. Firstly, in a form I call 'ethnographic footage', a spontaneous and descriptive reporting, although still selective as any footage. This is represented in roman font from the next section onwards. Secondly, there is writing as afterthought, analysis and reflection represented in italics. I am not privileging the second form of knowledge with its illusion of panoptic elevation from everyday life. Neither am I privileging the first form that either can take a flavour of 'authentic' anthropology or impressionistic flânerie. I am trying - from an analytical and pedagogical point of view - to locate two major forms of practice in writing. In reality the dam is not there and the river floods with reflection always already incorporated, as learned ignorance (Bourdieu, 1990), in even the most spontaneous and straightforward descriptions and observations.

\section{Conflict Education in Israel-Palestine}

Various formats of cultural and educational exchange between Jews and Palestinian Arabs with Israeli citizenship (approximately 20 per cent of the population within the Green Line) and Palestinians from the territories have over the last three to four decades become a more common practice among NGOs and municipal centres in the region. This can at least in some ways be seen as a means of bridging (or problematizing the gap) between, roughly speaking, two separated national groups. Jews and Palestinian Arabs (whether Arab Israelis or Arabs in the territories) do not attend their own schools. Only at the Israeli universities are also Palestinian Arab students. Two of the major institutions, the educational centre Givat Haviva and the only Jewish-Arab village Neve Shalom/Wahat al-salam with the educational and research centre School for Peace, have managed to present surviving, yet also changing and method-breaking, pedagogies and models of conflict education for several decades, which also have been acknowledged and discussed in research from the late 1960 s. $^{3}$ 
This article deals with an encounter workshop between Jewish and Palestinian Arab high school classes at Givat Haviva. The project is called Face to Face. Teachers and students meet at Givat Haviva with a group of facilitators, Jewish and Palestinian, for two to three days to conduct various activities and games around identity and culture, peace and conflict. The students are in these workshops, ideally, a mix of Jews and Palestinians and they work in large forums as well as small groups bi-nationally, facilitated by a Jew and a Palestinian, and uni-nationally where Jews are facilitated by a Jew and visa versa. Some workshops have pre-encounter meetings and preparations, and follow-up activity, but this differs. Also the pedagogic devices/activities are changed from workshop to workshop (as shown below) although the main framework is slower to change. ${ }^{4}$

\section{Report and Commentary}

The first encounter is between two Galilee schools, each south of the Sea of Galilee near the Jordan Valley: Kfar Manda (Arab) and Bait Zera near the Sea of Galilee shore. 27 students come from the Jewish High School Class, while only 15 join from the Palestinian Arab Israeli. Ideally, the organisers prefer an equal mix, but this is not always possible since some students refuse to participate. This number should not be seen as typical, since the Arabs, according to the organiser, Ali, are just as likely to participate.

I spoke briefly with the Arab course organiser, Ali (all names have been changed), taking Azmi, the director's, role. He still directs the project and it was he who allowed me to visit. I interviewed him last year. There is no co-directing Jew. Rebecca (interviewed in January 2000, who had the role as assistant to Azmi) has left.

Ali introduces me to Rachel and Helena during a smoking break and we speak easily. ${ }^{5}$ The facilitator role is 'authentic work', not 'guiding', Rachel says. She has been working with youth and NGOs for years, and she does not see her academic experience in the humanities as a bridge to this kind of work. Working in peace and conflict education seems to be about burning bridges to mainstream society, whether Jewish or Palestinian Arab. Rachel explains she has found a 'home' in Givat Havivaoutside she is seen as an 'extremist'. They work together, and there seems for her to be an agreement about how to work at Givat Haviva. The facilitators, though, had 'a very difficult meeting' about a month ago, but they are 'open to deal with the conflict', as opposed to the students who are not always willing to do this, according to one of the facilitators.

This time, the workshops run from 9 am to $3 \mathrm{pm}$ the next day, lasting two days instead of three or four. The timescale differs, depending on the financial situation of the schools, and time and the facilitators available and schedules on all sides. There is no strict timeframe. Jewish schools pay approximately $£ 30$ per day per student. Arab classes pay a little less because of their smaller budgets. The first half of the first day deals with personal, cultural issues. They 'have to know each other a little bit before dealing with the conflict', the facilitators say. They come with stereotypes. Jews think 
that the Arabs 'come with kiffeya [traditional Arab male red/white headgear]', Helena says mockingly. 'For the Arabs they see for the first time [Jewish] youth who are not soldiers'. They do not know much. Rachel said a Jewish student asked about the term Israeli Arab once: 'does that mean he has a Jewish mother?' For many Jews, 'Israeli' simply means 'Jewish'. It is not just an ethnic category, it is a national one.

You can hear 'voices of their parents speaking through their throats', Rachel says about the youngsters. 'They get a shock, a good one'. I ask questions about student expectations. The Jews 'want them [the Arabs] to like us', 'they will see we are not so bad'. The Arabs are less demanding, 'want the Jews to know us'. We talk about the difference. The know is important, Rachel says. She puts emphasis on the words I have underlined. The wordings reveal the underlying power relationship. The powerful wants to be liked. The disempowered wants recognition. The Jews do not need the Arabs and don't really need to worry about them; the Arabs need the Jews and see the 'knowing' as an important way of changing the nature of the relationship. The Arabs in Israel know about Jewish Israeli society and attend their universities and use their public authorities and work spaces. They speak their language; know where the cities are, and what they are called. The Jews do not know the Arab villages, Arabic or the other side in general. They are 'the oppressed', the silenced and silent other within.

The Arab school is from a mixed area, while the Jews come from a kibbutz settlement. The kibbutzim were established by the Ashkenazim, 'the elite of Israel', as Rachel says. She also says that the Mizrachim is 'a kind of other' in Israel. This divide echoes the relationship between The West/Europe/the Occident and the Orient, where the Oriental Jews are inferior even among Jews. It also indicates a complex character of several diasporas, several forms of home-creation, and the problem of constructing the Israeli state as a nation-state. This has implications for how to position the Arabs within the state.

Most of the sessions during these two days are bi-national, meaning that the Arabs and Jews work together. A few uni-national sessions are put in to work over/through issues addressed in meetings with the other. The sessions on the second day are dedicated to identity and majority-minority issues and to some of the country's regulations or laws on water, money, language, or national symbols. In other words, they approach the more overall character and identity, and the political 'state' of the state. Games/activities are changed from time to time.

Later I speak with another facilitator, Fadwa, an Arab Israeli who lives in Tel Aviv. Fadwa says that the Jews think they are doing the Arabs a favour doing this, while the Arabs come to convince the Jews. Generally, there is a good atmosphere in the beginning. This changes when they begin to talk about stereotypes. Interestingly, Stuart Hall notes $(1997$, p. 258) that stereotypes usually represent what is different from some 'other', a stereotype is a character reduced. Representations, on the other hand allows for complexity and a variety of form. The encounter allows, quite neatly, for activities that addresses the stereotypes as well as exploring possible representational development, as e.g. in the identity card and drawing the third map activity, introduced later. They try to keep the good feeling; you are okay (the group present), we are 
talking about the other people, is a typical attitude (Halabi \& Beck-Phillips, 2001, also mentioned by a facilitator during the informal talks). The facilitators explain that they are 'not teaching' but trying to help the discussion along. We help the teachers to continue in school, facilitators did not give them information. For the student, 'it is a study of themselves'. Another term, with which we could express the 'facilitator' role, could be moderator or mediator. 'Moderator' has been used by Ori Nir (Haaretz, 2002). 'Mediator' is a concept used in, e.g. 'Mediated Learning Experience'-pedagogy (MLE) (The Hadassha-WIZO-Canada Research Institute). ${ }^{6}$ The mediator is not involved with solving a problem at hand or 'filling up' the student with knowledge like petrol in a car. The mediator is instead concerned with, to summarise five main points of MLE: a) HOW the learner approaches the problem; b) helping the learners to see each other 'at the same level'; c) helping them to explore and interpret the significance of the issues discussed and accomplished; d) helping the learners to reflect on how they proceeded to reach, or failed to reach, those ends; and finally e) the mediator helps learners bridge one sort of experience to a new situation. ${ }^{7}$ In this sense the facilitator becomes a threshold host, or one who helps the participant to cross a boundary, in her, and as well to get into contact with the other. One can move further back to Piaget and the idea of leaping learning integrating a new scheme of understanding in the form what he calls 'accommodation', opposed to assimilation, where one 'fill up' according to previously established schemes (Falk \& Dierking, 2000), or Vygotsky's Zone of Proximate Development $(1962,1978)$ where the learner moves to a new staged when being facilitated/guided, a step she would not be able to make on her own.

I return to speak with Ali who is around thirty. He is doing an MA - which is a cooperation between Tel Aviv University and Neve Shalom's School for Peace-on conflict, counselling education and group social-psychology issues. He explains that they start off the encounter in Arabic, then in Hebrew. The reality is reversed. (Also noted by Halabi, personal interview and, with Beck-Phillips, 2001 as a method used in School for Peace high school encounters.) There are two languages, if we take English out, and they can perform any language they prefer. But in fact only the Arabs can pick their stepmother tongue, Hebrew, although with the effect of submitting to the Jews preferred language. By speaking Arabic, on the other hand, they can use language as a force. A question then arises when Arabic is translated: can you trust the facilitator? The Arabs are usually 'being shy'. 'If they chose not to talk, it is okay', Ali says. 'If they do not get the chance [to talk], it is my problem'. 'The work of the facilitator is to encourage talk', but not necessarily in Arabic for the Arabs. The students are sometimes using their teacher as counsellor. Ali has a disagreement with the director Azmi around the issue of teacher observation. Azmi has allowed them to be present. Ali would ideally want them out of the room. I mention that in Neve Shalom they have a second smaller room separated from the activity room by a mirror. Yes, he says, he has worked there, but it is not a solution. They can still get 'in contact', and it is better to leave them out, he says. The teachers seemed to be left on the sidelines, i.e. being 'students again' in the encounter, not being in control and learning something new themselves. 
I ask about the different phases of the encounter; the moods and attitudes. Ali draws an up and down curve showing a rather shifting, unpredictable development, moods diving and jumping. It goes mostly up in the beginning but then up-down, updown. The Jews are surprised that the Arabs do not feel Israeli, but Palestinian, when discussing identity or practising the identity games. 'The flag is not talking to them [the Arabs]', Ali says. They have some rights, but no national symbols.

What about the internal differences, do they get a chance to reveal, work with the differences and disagreements which exist within each group, I ask. They come as groups, he says. The Arab group 'need to put differences aside, because we are outside'. The Jews can easily be different, individualistic, because they are the strong ones, he continues. In this context the Arabs need unity. It is quite clear that the national narratives are being re-instituted and re-produced on both sides. Questions arise: it is not about whether they should deal with the conflict, identity and minoritymajority issues or not. It should play a role, apart from other less conflictual activities. The question is HOW to deal with it.

Ali explains that some students, as well as teachers, are afraid-located in ethnoscapes of fear. How will the group look at me, if I deviate? And the students are also affected by the 'what-to-say-to-make-teacher-happy' feeling which relates to the teacher presence issue discussed earlier. Rasan (another Arab facilitator) comes in and uses some Hebrew within the Arabic, such as 'fine' and 'okay' put in, just like Scandinavians include some English. 'You speak some Hebrew in between with your Arabic', I say. He smiles embarrassed; 'it happens sometimes'.

The students are divided into subgroups, ideally not more than 16 and with equal numbers, but there are fewer Arabs this time, and the group numbers about 15. I tell the facilitators that I want to watch, just as an experiment. I will watch body language, try to sense the non-verbal games, and maybe we can talk in breaks, I request. They approve with nodding, but contemplative acceptance, approving — but maybe slightly suspicious - to the odd idea. The students are giggling, looking. I smile back. They ask the facilitators why I want to be there if I do not understand them. The facilitators told them what I said. In the break, Helena says that in fact it is good, 'the students accepted me completely', and because she senses that 'I am not affecting the group dynamics'. So blind ethnography might be turned into an advantage - a way of trying to inhabit the myth of the fly on the wall. And this fly is almost seeing 'natural' behaviour.

Each group are mapping their region and lives by drawing on a large piece of paper. They can map mentally or more physically/geometrically: landscapes, cities, houses etc. Helena tells me that the Jews are usually more into the geometrical (not sure if she used this word) mapping. In the particular map drawn here, it is not so obvious, but she indicates that the Jews are into a more engineer-like precision - a modernist, urban mapping, one could say. The Arabs draw more trees, the Jews the characteristic, red-roof houses, typical of Israeli settlements, kibbutzim and suburban areas. The Arab villages are different, and their houses, as drawn, have no red roofs. Both groups are active and energetic. Facilitators stay outside. 
Afterwards they are going to put it together in a third map. An Arab girl picks a new large piece of paper and wants to start to produce a third, fresh one. Very interesting, I thought. Drawing a possible new space - a third space (Bhabha, 1994)? The supervisors then stop them. The girl talks with the Arab facilitator for a few seconds in Arabic, and after some friendly negotiation in the group, they start to cutand-paste, putting bits from each groups world on a third piece-which in a sense will be a new space as well. I notice that translation is used often, and that the facilitators have 'speeches' or statements in both languages. During the creation of a third map, there is a deadlock, where the Arabs seem more eager - desiring changewhile the Jews are leaning backwards, more indifferent. The scissors versus redrawing philosophy very much mirrors the political walking-on-the-spot. Should we share, separate or just slowly pacify the weak party? But they are dictated to cut-and-paste and finally they succeed. The Arabs are drawing the Star of David in a flag at some point and it is placed in the bottom. Quite a gesture to the Jews. The new drawing is basically just putting it all together. The re-configuration is only possible through a combination of extracts of the two drawings, not through invention from scratch. Wishes of a new world are played down and material realities taken seriously. The activity encourages forms of action or initiation in the Arendtian sense, i.e. working socially, in negotiation, with the existing reality in innovative and unpredictable ways. In the break, the facilitators explain that they would not let them start from fresh, since the past and the present reality had to be taken with them.

As a way of finishing the formal program of the day, each 'national' group is to present a performance. As predicted, the Arabs perform their traditional debka and the Jews their hora, a circle dance. The Jewish facilitator said during the break before the performance that the Arabs usually finish their preparation easily. They know their culture, but for the Jews... 'What is our culture?', Helena asked mockingly. The diasporic, heterogeneous character of Jewish history is here shown. Although united in a state, and a common religion, their forefathers' experiences were diverse. At some point during a break, Fadwa says: 'they do not know that I am Christian, and that is good'. The Arab students are all Muslims. Later they find out, and she felt the students altered their attitudes to the worse.

Later, after the evening dance performance, I speak to some students and teachers. There are three Arab teachers and only Nadim feels comfortable and interested enough to have a proper conversation in English. After some chat among all of us, I move outside with Nadim, and soon a group of students follows. While sitting on the bench Nadim diplomatically expresses that they are happy with the meeting, they 'did not come to solve', 'they came to speak', and they 'did not expect change', 'only to speak. It is the teacher's job to keep bringing up conflict issues in the school on an everyday basis, Nadim explains The Arab teachers come from an environmental and natural sciences background, and they have been playing with the idea of a cooperative environmental project with the Jewish class. Such snowballs within the encounter - an opportunity for crosscutting Arendtian action? (1958) - shows one 
of the beneficial sides of the workshop. They use the encounter to get acquainted, and to test if they can build something educational together.

An Arab girl approaching our space curiously tells me that she came here to 'speak Hebrew'. Suddenly more people come and my talk with the teacher now evolves into a big group discussion. Soon teachers and students get more critical or seem to speak more freely. The students were using my presence, initially, not to voice their inner angers or dissatisfaction, but as an opportunity for 'fun' and some English. And I am the one dragging them into issues with questions that may be too leading, like 'come on, tell me, what message do you have for the Jews tomorrow [second and final day], there must be something you want to tell them?' The first Arab girl, who came along, Habib, says: 'we are Palestinians, it is our land'. 'We are a minority but we have a right to live as other citizens'. 'We have our own culture', 'we are proud', 'we are citizens as well'. 'Next generation will change'. 'Now it will be the same [things will not change]'. 'We can speak with Jews closely here'. 'Not all of the Jews feel the same'. 'Some of them believe we can live together'. Some Jews 'feel superior'. I am a bit afraid of the presence of the teacher, and the fact that they may say things he wants to hear. Later I realise that there seems to be a special and honest student-teacher relation in this group, and that the students may be genuine. Ali, the facilitator, notices with surprise, that the relationship is unusually good. Very non-hierarchical I notice, although the teachers seem in control. The pupils do not take the roles as pawns in the game; however, we are still not close to the 'chaos school' where all behave like mighty kings and queens.

The message for the Jews is that 'Israel must leave the West Bank', Nadim concludes, leaving the diplomatic style. 'The enemies of Israel are our brothers'. 'It is a democracy for the Jews'. More Arab students come along; the Jews have left for their accommodation. There is not much convivial activity in the social/common hall where the dances happened. Initially, a few girls, Jews and Arabs, approached each other and had friendly dances. I get the girls to sing some Umm Kalthum and Fayrus, some of the few Arab singers occasionally I listen to. They perform easily. Ishmael, an Arab boy, performs in front of me to impress the girls, 'love is life, life is love', he croons. 'I have several girlfriends', he boasts. 'So you write Arabic [I wrote something down for him], so why do you not speak, what is the problem?' He teases, I speak some Arabic, but we don't get that far, and he starts dancing instead, to impress the girls.

Half an hour later I move on with them to a birthday party somewhere on the lawn. Candlelight on the cake glows in the dusk of the pleasant Mediterranean autumn. The Jewish group is absent. It is sad that it is so. This could be an important unofficial, spontaneous, off-the-record encounter. If they cannot find an excuse or occasion to socialise, argue or get acquainted, attracted, encouraged or discouraged, what is the point in coming? This seems to be business as usual. Nobody is being evil or confronting, or breaking the ice, just normal separation as all over Israel, where there has been a minimum of actual violent encounters (apart from during the first weeks of the second intifada), but certainly a conflict. According to other research 
accounts (e.g. Rustin \& Clarke, 1999; Halabi \& Beck-Phillips, 2001) the groups do in general mix. Rustin refers to the 'fight over tapes', when the official programme is over and dance happens spontaneously. Helena made a note, though, that they are always separate in the cantina.

'People generally did not seem that depressed', I comment late in the evening to a facilitator, when some Arabs are having their birthday party. 'Well, [sighing] we have to get on with our lives', he replies. This shows the resilience among Arabs, but it could also be happening in the Jewish group. Particularly for the Arabs, the visit to Givat Haviva is also seen as a break, a trip away from school. This inevitably makes the learning more informal and raises questions on the nature of learning outside or on the edge of formal learning settings. It is not necessarily an educational problem that workshops are seen as 'off school'. Other senses are opened, and the pressure of marks and achievement are temporarily gone. By offering non-achievement, alternative learning pedagogies for pupils and students and adults in addition to the educational system, Givat Haviva is, in this sense, similar to the Scandinavian 'folk high school'. A learning for life model, that is to say learning as living, as a way of conducting life, not to be confused with the concept of lifelong learning; a continuous (throughout life) upgrade of qualifications for professional use. Another point on the pedagogy is the situated character of the learning format. The participants are not placed behind desks to digest facts slowly and systematically. They are caught in tactical (de Certeau, 1984), social modus operandi (Bourdieu, 1990) situations. All becoming peripheral learners (Lave \& Wenger, 1991) in a rather unhabitual format forcing the participants to question or reflect on their given and integrated cultural and national attitudes.

\section{October. Second and last day, Workshop 1}

16 cards are spread on the floor. On each card a specific identity-component is written (in Hebrew and Arabic-I could read most of the Arabic) 'Ashkenazi', 'Mizrachi', 'Jewish', 'Israeli', 'Arab', 'Palestinian', 'Muslim', 'Christian', 'Druze', 'Zionist', 'religious', 'non-religious', 'human being', 'teenager', 'boy', 'girl'. I thought the last four were very interesting. The participants had to pick one card, and then three, they identified with. During the exercise there was a sense of indifference and lack of interest. An Arab guy picks 'Palestinian', 'Arab' and 'Muslim'. The most commonly picked cards were, however, 'Human being' and 'Teenager'. This might indicate an impact of the practice of encountering the other and realizing 'oh, we also have things in common'. The encounter introduces a profane lens of seeing 'the other'. He is not just a media stereotype, a border policeman, a stone thrower, or a historical figure from the War of Independence, the nakba, the Holocaust, or a Zionist pioneer and so forth. The 'other' becomes something else sitting there on his chair fiddling with his mobile in blue jeans. ${ }^{8}$ The discussion is becoming sensitive and that no one really wants to make the jump into an argument. 
A Jewish heavy metal hippie hybrid type at some point makes a nonchalant comment and one of the Arab girls strikes back. Soon they are into a controlled dialogue, the interest is growing and after a few minutes the students manage alone. Some anger arises and a Jewish guy leaves. The discussion is in Hebrew. Arabic is most often overrun when talk in the workshops becomes conversation in the form of responsive ping-pong. It slows down dialogue when the Jews have to wait for translations, and the Arabs speak Hebrew well enough. I sense the different accent, but the speed is about the same. In general the Jews are more assertive, interruptive and aggressive. In research on interruptive speech and speech forms this is named dugri speech: straight talking (Katriel, 1986; Zupnik, 2000). This phenomena is also felt in a later session.

The dialogue is very bumpy, low energied, and it seems as though it is the facilitators who slowly have to get them started. They are approaching the issue of land, property and home. It evolves into an argument. Generally the Jews are more offended, and the Arabs most often go into passivity. The Jews become tense more easily, close to shouting. Their tempers are unstable, often oscillating between tenderness and quarrel. The issue of the spoiled, lively, argumentative and assertive sabra Israeli, is an interesting thesis in itself, but here I would just outline an hypothesis: it is related to the sense of freedom, and freedom of speech and selfhood, the Ashkenazi Holocaust survivor would indulge their children with. Many of the first immigrants and their forefathers knew life under more restrained and threatened circumstances, often as a minority doing their business quietly, as a minority within other nations. Paradoxically, the Palestinians used to be the ones who did their business quietly in Israel, but now assert their legitimacy and identity and demand rights. Apropos:

'Arabic is legitimate', says Rasan, and in fact it is used a lot, although not as much as half of the time. The Arab facilitators have to work hard, especially when the Arabs have phases where they speak Arabic only. At one point, the Arab facilitator was collecting pens and paper from some of the Jews who were bored, fumbling with drawings as a way of getting through the day. After this, the energy rises.

I speak to Sarah, the Jewish female teacher again in the break. We sit on the lawn. 'We are separate people, we have to recognise that', she says. 'We cannot cooperate without recognising [this]'. She explained that she had been involved with an environmental education program and institute called Migal in the Golan, and, while Neve Shalom did not want to recognise Golan as being a part of the Israeli encounters (possibly because it is seen as occupied territory from Syria, lost in the Yom Kippur War, 1973), the school found it easier to switch to Givat Haviva, in case tension between Migal and Neve Shalom occurred. Givat Haviva apparently does not have these policies. Sarah, the teacher, thinks this is a good experience, to get to know the 'person behind', 'the person under the title, Arab'. She says that Givat Haviva had not helped with any proper preparation. It costs 164 shekels per person per night, Sarah says (about £25). Although disappointed with the lack of help for preparation, she said, however, that she thought the organisers were doing a good job, and that the price was fine. She wanted to use the experience to get into contact with other teachers and develop her own school project with the Arabs. This is one interesting 
outcome of an encounter, I think. Small, local snowballs, created in co-operation, with mutual benefit that must be a possible and aimed follow up, if any. Unfortunately, it is not common that the schools continue with projects together when the encounter is over. They go back to their separate worlds. Sarah wants to evaluate what the students get out of it, and Givat Haviva is not helping her. She asked for my help, and took me to the Arab teachers. We sat down together and I suggested a range of questions they could ask the students. They listened with interest, some translation went on, and they all wrote down in Hebrew, basic questions on expectations, experiences, good and bad ones, such as 'what have you learned', 'was there something you would have spent more time doing', 'how would you like to continue? The teachers might feel uncertain about their role in the encounter, their teaching relegated to observation, and therefore they seek some comments from the stranger, an outsider, however opinionated.

In the final session, they seemed to get through without getting into conflict. It was clear that they did not work very well together. The facilitators explained afterwards that this was a very hard group that the Arabs were weak and there were a general disinterest and lack of motivation. My memory sometimes kicks in when notes have not been sufficient. I remember an incident during the identity sessions, in which I sensed a quiet-before-the-storm atmosphere. A Jewish girl was responding to some of the Arab girls' statements about not feeling very Israeli. This disappoints the Jews, and this girl suggested that the Arabs should move away, if they do not feel a part of the state. Fadwa, the Arab facilitator, looked stunned, and, she explained afterwards, she was trying to control herself, keep calm, and just translate it to the Arabs. The tension in the group started building up when the Arabs emphasised their Arab and Palestinian identities and when they refused to agree that the state should be Jewish. The interviews I did, as well as other research accounts (Halabi \& Beck-Phillips, 2001), confirm that the Jewish Israelis commonly get surprised when the Arab Israelis assert their Palestinianness. The sharpening of the Palestinian identity among Israel's Arabs comes as a shock. This is often followed by 'loyalty oath' questions from the Jews, around e.g. what side they are on in a case of war (Rustin \& Clarke, 1999).

\section{October. Workshop 2. Day 1 of 2}

People arrive in the morning looking bewildered. 'They shot Gandhi.' This was the morning when Israeli Minister of Tourism, Rehavam Zeevi, was assassinated in a Jerusalem hotel room. 'Gandhi?', I ask, puzzled. He looked like him ('Only physical similarities'), but his political views were him, one explains with a sarcastic grin. The schools are late, and so is one of the Arab facilitators, Rasan. Some of the facilitators think he might have been caught up with roadblocks on his way from his home in Tira, an Arab city close to the West Bank border.

I get some information about how things ended last time. According to the program, or the most usual program, they are supposed to finish by writing a letter 
about their experience. This was what Rachel said. But in the final session something else happened. They changed things and talked about the biology/environmental cooperative project. It was probably a good choice to help along what the schools wanted to do in the future.

Rachel helps with a rough translation of the Hebrew text of the program (see Appendices). Hebrew text. The Jewish facilitators do not know much more Arabic than me, if they know even that much.

Rachel, 'already smoking too much', as she says, returns to the Gandhi story. 'Let us see how the events will affect us'. 'It is not unusual with a bomb during the workshops'. 'Haifa University will observe us today', a facilitator says. Oh, more intruders sticking their noses into this. But actually no ethnographers came today. Instead a questionnaire was given to the facilitator on day two for distribution to the students. Rachel now says that the Arab class is coming for the second time. This kind of meeting is not made for second timers, she moans. The Arabs will be disappointed tomorrow, and for the Jews it will be a fresh experience. I am puzzled. Why are they doing this? Rachel reckons it is the lack of participation from Arab schools at the moment which forces the organisers to do tricks. During the encounter it doesn't seem to play a role though. This meeting proved to be, as my report extracts will show, quite dynamic.

While waiting for Rasan, I ask Rachel about deviances from the program or from usual facilitation. She says she has tried to facilitate alone, with no Arab partner, a few times during the three or four years she has been here. But the point of the pedagogy is the symmetry of participants and facilitators, when everything else is asymmetric (power, language etc). The model seems to compromise its own principle in order to be able to run workshops in this difficult reality? When Rasan finally arrives we all gather outside. $^{9}$

I join a new facilitator team, this time headed by Rasan and Rachel. Rasan introduces the workshop in Arabic, and then Rachel does the same in Hebrew. As is the most case of the Jewish facilitators, Rachel does not know Arabic. This is typical for Jews in Israel, although I find it surprising that Jewish facilitators here, in this profession, are not better equipped. Most of the road signs in the country are in Arabic as well, and it is their second, official language. The Jews have Arabic in school for one year. Anyway - Rachel is an extremely sympathetic and nice woman, and I was impressed by what she was doing and still is today when editing my afterthoughts further for this article.

Again the Jewish group is a bit larger which puts them in the majority position, mirroring reality, although the aim here is to arrange them in equal numbers. There are about 16 in the group, 10 of these are Jews. The atmosphere is amazingly calm and relaxed. There is a lot of giggling and many smiles and no tension. As last time, the group forms a circle in the room. The Arabs sit together as do the Jews. Rasan, though, sits in the Jewish half circle and Rachel in the Arab section. There is a 'name round' where they discuss what their names mean. They continue with a game: one person begins by saying his/her name, and then the next has to say their name, the 
next three and so forth. Everybody leans forward and participates with smiles and curiosity. There is a lot of laughing about funny pronunciation. Then the name game is taken even further-is this necessary: A girl stands in the middle with a piece of paper, and says a name while dropping it, then a guy jumps up and has to catch it before it touches the floor. If it reaches the floor, a 'slice' of the paper has to be taken off. They all behave like kids on a summer school camp, and there is no conflict at all at this stage. Next, one person from each group goes outside with Rachel. They stand in a close circle hand in hand, mixed, I have missed the point. A girl comes in, tries to break in, then a boy comes in, lots of laughing, facilitators leaving. Rasan and Rachel both smile in a relaxed matter, rather routinely. It shows they have tried this many times before-but they seem really to enjoy this moment of the encounter.

A new activity with two circles (one inside the other) is introduced. The people in the inner circle face the people in the outer circle. Circles are moving around in opposite ways, and people are shifting around. They have talks face to face on boy relations, girl relations, boy-girl relations and family. All are amazingly active and joyful. The youngsters all had sparkles in their eyes. Rasan comes over: 'a very active group', he says. A Jewish teacher comes in, but she doesn't seem to affect the group dynamics. It seems like this kind of work is happening in Hebrew only. The facilitators cannot be in each group translating. It looks like chat and play, not discussion or argument. The conflict politicises culture, but these youngsters may also, now and then, have had enough of that reality. Later some of them start comparing mobile phones. There is a final talk in the wide circle. There is a drop in energy level after an hour. Girls play with their hair, giggling. Generally, as in the first workshop, the girls are more dominating and they also outnumber the boys. Their body language, especially among the Jews, is more expressive than amongst northern Europeans of that age, I dare to conclude without, however, spending much time with that age group anymore. (today, I see mostly Swedish university students at Malmö University with a more reserved body language-at least to begin with). The Jewish Israeli girls here unfold their bodies and souls immediately: not afraid to refer to their feelings and experiences by pointing fingers, or bending their wrist and hands toward their chests. They are a lovely bunch, these 16-17 year olds. In all of them I sense an odd dance between child and adult, two voices, sometimes singing together in disharmony, while at other times one of the voices takes over. The 'adult' wants to speak, but the child has been in business for longer. There is a twofold internal, Bakhtinian, dialogue: in one sense the child-adult negotiation. In another sense there is the peer-pressure against a stepping-out, the individual taking another stance, initiating on the border of, or outside expectation and socialisation. But then again, particular agencies-also drop outs (hippies) or 'uncalled' (bikers) (Willis, 1978, p. 7) need a structure or sub-structure to support it (Lovell, 2003). Related to this is the Freireian process of making the group 'knowing', the conscientização, ${ }^{10}$ referring to an empowerment of the group-in this case particularly the Arab group since they are inferior, which undermines or discourages individuality. 
Just before the break people were talking about stereotypes. The Jewish girls expressed positive surprise about the Arabs; saying 'oh, you do not wear headgear, you've got boyfriends'. The Arab girls had said something about having boyfriends in their twenties, 'you are all fixed up [addressing the Arab girls]', Rachel quoted the Jewish girls. The Jews are not aware of how Arabs in Israel live today. In Stuart Hall's sense (mentioned earlier) both parties do get a chance to play with stereotypes as well as 'representations' here. After lunch they continue with a drawing exercise in which each group is supposed to produce images of the other, and another drawing where they try to represent the particular group/other present today. The paper remains blank in the Jewish group, while the Arabs each work energetically on separate pieces of paper, though also talking. I ask Rachel why this is. She says that the Jews are having a really good discussion and are trying to decide collectively. While they draw, and I nosily leave my chair in the corner and look over their shoulders, I can observe other things as well: generally the Jews are more individualistic, expressive in their different styles, both boys and girls. The Arabs are more on the chewing gum wagon though. There is no piercing in the Arab group. Among the different drawings on the floor I noticed portraits of the Jewish religious other (men in black), many kids, the Star of David, a Hanukkah candlelight, veiled Arab women, Jewish women with strings of pearls waving scarves. Jews decided to put their separate pieces of paper into one drawing. The drawings reveal, on the one hand, that each part rely on stereotypes, and yet the encounter, on the other hand, presents 'fresh impressions', inviting both parties to negotiate old and new material: the expected or frozen image of the other is defrosted through her very appearance in person.

In the following discussion, the first signs of tension are shown. A dominating tall and beautiful Jewish girl asks for ivrit, the Hebrew name for Modern Hebrew. In English translation, just 'Hebrew'. The Jews ask again for ivrit. They are suddenly more aggressive, and they do not understand the Arab response, which is not harsh, but showing puzzlement. Games and activity stops. The facilitator let this train run, the group is really working: 'ivrit', 'aravit', 'anglit' (Hebrew, Arabic, English). The three guys in the Jewish group are silent for most of the time. Some Arabs show disinterest or retire into quietude. Rasan unsuccessfully tries to stop the discussion. The whole thing kicked off, when one of the Arab girls started to speak Arabic and Rasan then translated. Some of the Jews wanted Hebrew only. 'This is a Jewish country'. 'This is Eretz Israeel' [the land of Israel]. It is the language of Zionism, borrowing from the bible, the Promised Land, in order to realise a political, national project. The words, 'Eretz Israel', occasionally shouted, also make up the first two words of the body text in the Declaration of the State of Israel. You have to speak this language, and you have just shown that you do it fine, what is the point with Arabic?, some in the Jewish group point out. When Arabic is spoken for more than ten seconds, the Jews become impatiently insecure, and begin to terrorise the dialogue and speak internally-again applying interruptive dugri style (Zupnik, 2000, p. 85). When harshly requested by the Arab girl brigade to speak Hebrew, the Arabs seem more 
passively puzzled, than seriously provoked to fight back for the right given by the facilitators. They do not get angry, they just pull out and stay silent. The situation is complex, because it appears to be a chosen silence - a non-interruptive musayra style (Zupnik, 2000, p. 85) - and a means of handling the situation, a 'tactic' in de Certeau's sense (1984, p. 37), since they are trying to gain some power in a situation where they are in a minority and have been put up against a wall by the Jewish Israeli demand for Hebrew. A series of interviews conducted before as well as after this encounter lead me to the conclude that the Jews are surprised, discomforted and angered by hearing Arabic in Israel. This shows how much Zionism is incorporated and naturalised, and how much the national approach is rooted. The issue of post-Zionism and the colonial settler state might be relevant to the facilitators and academics, but for the Jewish youngsters such ideas are not a part of their world view. It is very hard for the facilitators, in such a short time, to create a breakthrough, to disrupt or deconstruct the onedimensional language.

When there is a break, I ask the two facilitators straight away why they do not intervene more. They reply, in chorus, that they will not teach, only facilitate. This relates to Mediated Learning Experience, explained earlier. Rachel said afterwards that the Jewish group did not allow the Arabs to 'speak a word of Arabic'. 'This is a Jewish country, you have to speak Hebrew', she quoted. Rachel is excited, saying that it is the best session I have ever had, they are dealing with the real issues, and they are not even aware'. Rachel might be suggesting that the students are not yet conscious or reflective about the impact of the experience. This means that, even though confusion and confrontation is created between both parties, a learning process that will continue at home has just started. That is a good thing. Education is a process, quoting a former Givat Haviva facilitator working on the two-year project, Children Teaching Children (CTC), not 'one-off' encounter projects, which could be damaging, he explained. The mainstream Israeli educational system provides a Zionist process. The encounters can not provide a questioning process, but they may trigger it, although the former facilitator of CTC was sceptical. Encounters do not provide time or techniques for re-configuring processes in the Ricoeurian sense (1983), and maybe they are not providing time enough for other speech genres, a new language around the conflict, to develop, in the Bakhtinian sense (1981, 1986). I would say that the ruptures the encounters create are a start, and in some ways these brief encounters work as temporary 'historikerstreits' ${ }^{11}$ where young people get a chance to go beyond their identities and the histories they grew up with. Not an easy task, however, at a time in their life where identity and their own history is formed.

The youngsters enjoy a relaxing coffee break in separate groups and afterwards something interesting happens. The Jews come in first and instead of forming a half circle of Jews versus Arabs they disseminate themselves covering the whole circle. A seat here and there is free, not a cohesive section as before. The Arabs they look puzzled, where is my seat, where is my(!) group? The Jews are sitting there with quizzical grins. I have my thoughts about a cunning Jewish plan, but also thinking that they may have been told to change places. They had not, I am told afterwards. Rachel explained that the Jews tried to weaken the Arabic 'bloc' by separating them. She recognises the 
cunning plan with a trace of disgust in her voice, and sneers 'they mirrored Israeli policies'. They were fragmenting the Arabs, also a minority in the encounter, into subunits, just as the Israelis call them Muslims, Christian and Druze or place strategic roads and settlements in the West Bank, splitting formerly cohesive Palestinian areas into bantustans. The meeting thereby cruelly reflects the macro-politics, unless pedagogies and facilitating means are put in play to go against it. Lower Arab numbers make it quite difficult to work against the macro-situation, which all participants clearly carry, in their bodies and minds, into the encounter. The little chair game reminds me of Rabinowitz (1998) writings on the Judaization of the Galilee, the strategies against the Bedouins of the Negev (Abu Saad, 2000) and as well the Ashkenazi elite's policies against the Oriental Jew in the 1950s and 1960s (Yiftachel, 1998).

I wonder why the tough-looking Arab guy does not speak at all. 'What is wrong with him', I ask Rachel. 'I think he is dumb', she says. That is all right or normal, she explains 'he is 16 ' she shrugs dryly. In the new formation of the class, in which the Jews cunningly fragment the Arab unit, the discussion continues. There is a lot of bevakasha (please), beseder (okay, good or yes, depending on the context). Some more drawings come out from the game that was abandoned over an hour ago. The game was stopped spontaneously because of the discussion. Now the Jews portray Arab stone throwers, masked men, police, women veiled in black completely, a mosque with the crescent moon, the characteristic Israeli red-white patterned road stones; another typical Israeli cityscape icon. The Arabs have drawn women wearing daring bathing suits, and orthodox, kids, and the Star of David, as earlier noted. Each group looks sceptical and a bit reserved after the presentation. They enter a discussion about Judaism and Islam. The Arabs look bewildered and lack confidence. There are fewer of them in the room. The Jews argue amongst themselves as well. The tall girl, Mona, is attacking Islam, and they are now approaching issues in the light of the September 11 attacks as well. Rachel tries unsuccessfully to enter the discussion. Mizrachim, ideology, conflict. They debate all the hard issues now. The Arab group has stopped speaking. Benjamin, a Jewish guy, is on the edge of this group, trying to correct the girls without being too deviant, without alienating himself from the group. At some point, the Jewish girl brigade stops speaking as well. I spoke to Rachel about Mona, the tall girl, during the next break. She has got 'a lot of fears. .,', 'she is not focused'. Later Rachel explains that Mona had experienced a stone throw attack while riding in a car with her mother. No one got hurt, but it has marked her. Students get a chance of writing themselves in, they get a chance to be heard and speak to the other, which is good, but the perspectives can lead both parties in separate emotional trenches.

After the break, the Arab group stays away, while the Jews sit waiting. Rachel is expecting a boycott. I go to the hallway outside and look out the window, and down there on the lawn in the sunshine stands Ali grinning. The Arab group comes in, after Ali went down speaking to them. Back in class the Arabs now speak Arabic more often. The facilitators are silent. There is quiet. Finally, Rasan speaks, followed by Rachel. The facilitators start to ask the numb Arab girls questions to get them to speak - a hippy- type has stayed silent and close to Mona most of the time, a joiner? As 
noted earlier, the Arabs, in this case the girls, chose silence as an empowering tool, to create frustration in the Jewish group, and that was successful. Silence, in the form of quietude, is not a blind accept of the situation, but a protest of non-participation, like a hunger strike. A typical tactic of the dispossessed. Today there are as many Palestinians in Israel as there were in 1948 before al-nakba, and they are just starting to overcome the silence. The Palestinians in Israel are not really connected to those Palestinians in the territories who are in the midst of the struggle. They are not the Palestinians on the barricades, not the loud Palestinians, but more comfortable or less uncomfortable hybrids, sympathising with their brothers and sisters. This subgroup in the workshop seems to have reached a 'should-we-stop-or-continue' point, a strange impasse. The facilitators seem to want some premises or conditions to be met or agreed upon by all of them. Then Rasan leaves with the Arabs. An unplanned, uni-national session now takes place.

The talk in the Jewish group is heated and there are internal differences which can more easily find expression now that the group is on its own. I went to the Arab group as well, but they got distracted, began to approach me, smiling and giggling. It is, in general, easy for me to get eye contact with the Arab pupils, while the Jews seem more indifferent about my presence. I seem to destroy the group dynamics, so I leave. Just before that, an Arab boy was grabbing my notebook, not aggressively, he just very much wanted to have a look, understandably. What is this nosy spectacled guy doing? He cannot even understand what we say? I let him, 'go ahead, but you can not read it anyway' I say (I hardly can myself). Rasan interferes hastily, takes the black book away from him and hands it over to me apologetically.

In the Jewish uni-national session, it seems to be boys against girls. Back in class, in confrontation, Mona is now shouting. Mona, leading the girl brigade as usual, points fingers towards her temporal bones several times, and the Arab girls are speaking again. Mona is addressing Rasan. The most aggressive Jews are leaving. 'Ma as-salami' (goodbye, peace be with you), an Arabic girl says with grinning irony.

The two groups are of equal size now, there is a ceasefire and calm and more respectful dialogue emerges.

Some of the Arabs are now for the first time allowed undisturbed speaking time. Maybe they now listen due to exhaustion? Facilitators slowly take over. They are explaining something. Teaching?

'What do you think of this fucking Israel', Ibn says afterwards. He is a chubby Arab boy with a mild face, and it surprises me to hear this point as the first thing to come out of his mouth during our conversation. I try to play the ball back to him, and start a conversation about this and that. 'I can speak Hebrew if they have a problem', he says. 'It is the same', 'I did not expect anything'. I ask about his expectations for tomorrow, 'none', he replies. 'Why did you come here', 'to get a break [from school]', he responds laconically. Finally we talk about the final part of the session, after the ceasefire, when all was calm conversation. The fact that some of the Jews left changed the atmosphere, he explains. It became more equal. 'I could relax', he says. It was 'leisure'. I am not sure he picked the right word to express what he meant here. He meant 
'not threatening', 'not uncomfortable'. Rachel says that in the final time, after the Jews left, they were experiencing a 'catharsis'. She is confident about her choice of word!

Late in the evening after this first day of the encounter Ali is having an informal evaluation back at the office with some of the facilitators. According to Jacob, the new facilitator - who said he had a really hard day-Ali was asking people to be more organised, work more as a team. It is very complex, Ali had lectured. You have to be calm, he had pledged. His impressing fast Hebrew with an Arabic accent is ended with a sudden, guillotinic end: layla tov (good night).

Jacob and I have been put in the same room tonight. We walk back in the dark, and Jacob says that his group was okay, but that 'the Jewish students hated me at some point'. 'They thought I was Arab'. At some point he said jokingly 'kill the Jews'. Is he as also one of those self-hating Jews? The participating students, on both sides, are observant and curious to learn if, and to what extent, they can gain support from their respective facilitator or maybe both of them. The Jews are puzzled by the fact that the Jewish facilitators did not represent typical or mainstream Jewish Israeli attitudes, and that they did not blindly accept the Zionist national perspective. Instead, they facilitate or encourage the students to look for other options and adaptations and to reach for the traces and premises of their arguments. In that sense, they are covertly post-Zionist, encouraging a fresh reading of Israeli history (a Ricoeurian reconfiguration?): unturning the taken-for-granted stones of Zionism and the War of Independence. For the Arabs this was 'the disaster', 'nakba'. A more detailed analysis of the language spoken would reveal more about the character of the student-facilitator relationship. The quote above, however, reflects the disappointment in the Jewish group with 'their' facilitator. He was not what they hoped he would be: an adult representative or ambassador of their opinions, someone to lead them in this meeting with the 'opponents', the Arabs.

\section{October. Second and last day, Workshop 2}

Some of the Jewish students, primarily from the subgroup I have been following, have been sent home for smoking hash the night before. Unfortunately, I did no participant observation here. The Jewish group is a bit smaller today. The quiet, hippy girl, sitting next to Mona for most of the sessions, is gone. I was saying to Rachel that I sensed she was very supportive of Mona. Rachel said that she was not in particular supportive, but she was a 'groupie'. This led me to other thoughts about peer relations and the sizes of the group and the emphasis on social processes. The encounters might gain from adding work in smaller units, with two, three or four participants, so the participants could get a chance to work more on the individual level, to get to know the other as person and get to know his/her unique story. This is not to be confused with a level that avoids the macro conflict. We could call this the interpersonal level (opposed to the present intergroup approach, explained and favoured by Halabi \& Beck-Phillips, 2001, Halabi \& Sonnenschein, 2004) although it is still about conflict and groupformations, but addressed through the individual human being. Together with the existing social approach, we are close to what Sagy (2002) calls the interactionist 
approach. To expand with many smaller units, all facilitated, would raise the cost of running the encounters, since they would need more facilitators, as Helena said when we discussed this issue.

Arabs are accusing the Jews of repeating crimes against Arabs which the Nazi regime did to them (translated by Rachel in retrospect). Things move to a deadlock. In the next bi-national session there are five Jews and six Arabs. I don't know where the rest are: did they just have enough of it - or have they been sent home for smoking cannabis? The girls arrive late when the session has started and are asked to leave. Now the identity game with cards on the floor finally happens. It was supposed to happen yesterday afternoon. They can pick any card they feel affiliated to. So the rules applied are slightly different than during the last workshop. The most obvious one for them first and then they can just make a prioritised list. The Jewish group answers: 'Israeli', 'Zionist', 'Jewish'. The Arab group: 'Palestinian', 'Arab', 'Muslim'. Again there is a strange impasse. The pupils are waiting for someone to break the ice. The facilitators are being quiet. Suddenly someone initiates. If you think you are Palestinian then move[!] is the message from Mona. The Arabs participate more now, and the Jews have accepted that Arabic is spoken and facilitators are translating. At some point a few people on each side start leaving. Benjamin, a Jewish guy, stays.

I approach him during the coffee break and ask him to elaborate on some of the issues. We start talking about language. Benjamin explains that the day before some of the girls had asked the Arabs to speak Hebrew. 'Some did not ask so nicely and some did'. 'The girl asking not so nicely said that Jewish is the national language'. 'In fact there are two: Hebrew and Arabic', he explains carefully. 'And Russian is getting there', I say. He laughs. He says that he came here to 'learn about the other' but also 'your self' and he continues to explain that he 'did not agree with the group'. There was a problem with the other boys. One said 'we treat the Arabs nicely', and Benjamin did not agree. He explains that he lives in an area where there are many Arab villages, he did some work for a movement in Misgav where they tried to bridge the groups and they went out together. 'We did not speak politics', he said 'but you cannot leave politics out'. I ask him about what he has learned here, and he doesn't succeed in coming up with an answer. He looks thoughtful, contemplative, saying, 'I'll have to think about that'. I show my sympathy, while leaving him, returning to the next session. Some of the participants are really working and thinking-and also learning... something?

After the final session, Rachel explains that Mona was talking to these Arabs as it they were part of one national group of Muslims. A long time they were circling around a 'suggestion' mentioned a few times: 'If you do not feel Israeli, why do not you leave?' This is the loyalty issue, which addresses where one's roots and primary identity lie. The facilitators could help the students acknowledge and negotiate the complexities of the identity-picture. The identity card-game should help here. Each person can be coherent, and yet inhabit difference (using Pieterse, 2001) and paradoxes. The Arabs were responding by saying 'I am Palestinian, I was born here'. The Arab silence the first day was partly — as earlier commented - a tactical reply to the attack, 
and partly because they were caught in a situation where it seemed to be the only option. They had a hard time expressing themselves fully about the issues, Rachel said. And they found out that they could use silence as a 'tool of resistance', 'to make the Jews frustrated' - the weapon of the weak!

\section{Conclusion}

The peer group relations and strong anxieties present on both sides seem to make it unbearably hard for either side to unzip the straitjacket of national discourse of group against group. Conflicts are often holding the internal differences in each group together, and the encounter structure furthermore supports the group against group confrontation. It also supports dialogue, certainly dialogue about conflict. But how is conflict, on many levels, to be dealt with and spoken about if the talk is to remain dialogic? The encounter workshops create an open space for anarchy and verbal fight. Rather than providing a safe space for dealing with the issues carefully, unpacking the known and the unknown slowly, the workshop room provide ground for re-action, or an acting out, different from durcharbeiten. ${ }^{12}$ It might be seen as a third space (Bhabha, 1994) in its most progressive and constructive phases, but it is rarely so. Only the binational sessions seem to leave a door open for heteroglossia and ambivalence, the suppressed features of the type of identity-formations and approaches which the encounter projects should support in order to be constructive and dialogic. But time is short and the groups are too big. There are a lot of personal fears which could be worked through therapeutically in parallel with, or even before, the social processes.

The 16-person forum is challenged by its inherent tendency to give voice to the loud and marginalize the not so talkative. In general there is only limited space for individuals to really show who they are. Recognition of the other can more easily be built upon a more thorough experience of the other, as a person and member of a group (the interactionist approach, as referred to by Sagy, 2002). The encounters might seem more fruitful for all parties if they were better prepared, supplemented with smaller unit work, and they also require more time! Time to prepare and time to work in the schools and meet again and again. Each person needs to be trained in listening, in turn-taking, in the historical background, to be able to discuss appropriate cultural material. The organisers could, for example, introduce literature, movies and music, and expand the processes/methods used in photo language game. The photo game was not on the programme in these particular encounters observed, but it is a typical activity.

In terms of viewing the encounter as a paradigm for a revisionist reading - here understood in the line of New Historians, critically looking at Zionism (Pappé, 1999; Silberstein, 1999) - another detailed analysis of the discourse would be needed. To do this it is clear, however, in the texts and interview accounts, that is this indeed what is on the cards, but at the same time the group versus group approach tends to cluster all the differences in two opposing monologues, which defies the rich heterogeneity on both sides and blows out the single, radical candle of post-Zionism with one shout, 
'Eretz Israel!'. This leaves the rest of the encounter in the dark ages of Zionism, with which there is no other response to than a similar, narrow Palestinian nationalismthe backlash of the intergroup approach, a bit too uncritically endorsed in e.g. Halabi \& Beck-Phillips, 2001; Halabi \& Sonnenschein 2004, and more interestingly questioned by Sagy (2002) and indirectly by Shuli Dichter (2001, interview).

The issue of silence or avoiding narration, which has been brought up several times in this article, could indicate self-protection. The agents are here reluctant to 'tell' or express the unpleasant, as seen in the interviews and in the two workshops, as if they - quite understandably - are afraid to open a wound (Nelson \& Horowitz, 2001, p. 307). The speaker may speak in a condensed, enigmatic way or just speak via the silence. They step in without stepping through, and by that they perform defence, insecurity, fear - and maybe as well a tactical power.

During the final lunch the two groups sit in separate parts of the cantina.

\section{Acknowledgements}

Thank you so much to all students, teachers and facilitators involved in the encounters dealt with in this article. Also many thanks to all the other people in Israel-Palestine whom I have been lucky to meet, spend time with and learn from.

\section{Notes}

[1] This article draws upon my PhD in cultural studies addressing means of alternative conflict education in Israel with empirical field work at the educational centre School for Peace, at the Jewish-Arab village Neve Shalom/Wahat Salam and the educational centre Givat Haviva. I focused in particular on a two-year junior high school program and two to three high school encounters, and interviewed project facilitators, teachers and students during 1999, 2000 and 2001, i.e. before and during the present intifada. During the final visit I also observed activities, approximately from start to finish, in two encounter projects, each two days long, at Givat Haviva. The year before the outbreak of the intifada, just before I arrived, had led to postponements of encounters and made me concentrate on interviews. Interviews were conducted in English.

[2] The facilitators of the programs at the two institutions investigated most commonly use the term Palestinian when they refer to Arabs with Israeli citizenship, but not consistently. Rabinowitz (1998) notes that by using the term Palestinian you indicate a particular branch of Arab identity, and equalizes the 'Israeli Arabs' with Palestinians in territories in terms of ethnicity, and makes them a stronger unit as a whole, and furthermore makes them visible as a specific ethnicity within Israeli society. Increasingly, Arabs of Israel define themselves as 'Palestinian' (Givat Haviva survey 2001, own interviews 2000 and 2001). By using the term 'Palestinian' they also express a more specific territorial affiliation and belonging with the inside-the-Green-Line-area, nowadays mapped 'Israel'. Some mapped enclaves of 'Palestine' are to be found in various zones - temporarily under full or part Israeli territorial ground (and air) control - in the West Bank and Gaza. Points here were inspired by discussions on map and territory at www.uel.ac.uk/londoneast (2005). See e.g. Phil Cohen (2005). Names on interlocutors mentioned in this article are changed (except for School for Peace director, Rabah Halabi, at Neve Shalom/Wahat al-salam, and former directors of Children Teaching Children programme at Givat Haviva, Shuli Dichter and Jalal Hassan). 


\section{A. H. Hansen}

[3] For example, the following material available in English (or German) has been used: Amir (in Weiner et al., 1998); Hewstone \& Brown, 1986; Hall-Cathala, 1989; Feuerverger, 1998 and 2001; Abu-Nimer, 1999; Rustin \& Clarke, 1999; Maoz, 2000; Halabi \& Beck-Phillips, 2001; Sagy, 2002. Most of the post-2000 work still concerns field research done before the present intifada.

[4] There has been a main division between interpersonal and intergroup work, described in e.g. Hewstone \& Brown, 1986; Abu-Nimer, 1999; and Halabi, 2001. Sagy, 2002 proposes a third way called the interactionist approach.

[5] No tape recorder was used during the informal interviews, while a series of other interviews outside the encounters were recorded.

[6] The five points are my summary from the Institute's website www.icelp.org/Pages/ WhatIsMLE.htm

[7] Notes on clothing: a few Arab girls wear hijab, but in general they are as Western and casual as the Jews. One Jewish and one Arab girl both wear t-shirts with NIKE logos. The young people's style is not so different from any other Westernised culture, a result of an ongoing cut and paste unfolding new hybridities on the ground, more complex than the discourse of separation and difference.

[8] Givat Haviva looks like a countryside campus or a summer camp school, with lots of trees and green grass - the latter, as in Neve Shalom, is just another example of the Europeanization of the Israeli Middle East landscape, tamed by the Jewish Ashkenazi designers of the country. It is reminiscent of American university campus, and most of the water need to keep the grass green comes from the West Bank. The buildings and the trees are different, though, looking rough but attractive, and the whole area is spacious, at the same time having many cosy, intimate spots where people can have a quiet talk under a tree. The Arabs and Jews are arranged in separate groups, glancing sometimes at each other, but without much curiosity or tension. There are differences in clothing, particularly between the Jewish and the Arab girls. The Jewish girls wear less. None of the Arabic Muslim girls are wearing hijab this time, as in the previous encounter.

[9] The term conscientização refers to learning, or a process of developing a critical consciousness, where the subject learns to perceive social, political, and economic contradictions, and to take action against oppressive elements of reality (Freire, 1996, preface).

[10] In Germany in the 1980s a debate about the history of the Holocaust in relation to contemporary German identity and responsibility took place (see e.g. Mayer, 1988). The new historians in Israel, such as Morris (referred to in Hass, 1999) and Pappé, 1998, and the post Zionist debate (e.g. Silberstein, 1999) is in a similar way Israel's historikerstreit. Especially during the Oslo accord years, when there was an atmosphere of some progress in the JewishPalestinian relations, Israeli actions during the war in 1948 and afterwards was questioned, not just in academic circles but also in newspapers.

[11] A point made by Eleonore Kofman. Personal conversation 19 March 2001.

[12] This point is inspired by a distinction, made by Bill Schwarz (1999), between acting out and working through, where the acting out is merely a repetition of an unconscious memory, while working through also deals with the vaguely known and the conscious memory. A working through is then - in my adaptation - also about trying to unpack and analyse spontaneous and naturalised behaviours, and looking at the causes and motifs of instinctive acting out.

\section{References}

Abu-Nimer, M. (1999). Dialogue, conflict resolution, and change. Arab-Jewish encounters in Israel. New York: State University of New York Press. 
Abu-Saad, I. (2000). The Bedouins and the State of Israel. In Sikkuy's Report on Equality \& Integration of the Arab Citizens in Israel 1999-2000. Jerusalem: Sikkuy.

Arendt, H. (1958). The human condition. Chicago: University of Chigago Press.

Bakhtin, M. (1981). The dialogic imagination. Four essays. Austin: University of Texas Press.

Bakhtin, M. (1986). Speech genres and other late essays. Austin: University of Texas Press.

Bhabha, H. (1994). The location of culture. London: Routledge.

Bourdieu, P. (1990). The logic of practice. Oxford: Oxford University Press.

Cohen, P. (2005). Are we that name. Retrieved on 14 May 2005 from http://www.uel.ac.uk/ londoneast/publications/Discussion/AreWeThatName.htm

de Certeau, M. (1984). The practice of everyday life. Berkeley: University of California Press.

Falk, J., \& Dierking, L. (2000). Learning from museums. London: AltaMira.

Feuerverger, G. (1998). Oasis of peace: A community of moral education in Israel. In E. Weiner (Ed.), Handbook of interethnic coexistence. New York: Continuum.

Feuerverger, G. (2001). Oasis of dreams. New York: Routledge Falmer.

Freire, P. (1996). Pedagogy of the oppressed. London: Penguin.

Haasha Wize Research Institute (2003). What is mediated learning experience. Retrieved 2003 from www.icelp.org/Pages/WhatIsMLE.htm

Halabi, R., \& Beck-Phillips, U. (2001). Identitäten im dialog. Schwalback: Wochenschau.

Halabi, R., \& Sonnenschein, N. (2004). The Jewish Palestinian encounter in time of crisis. Journal of Social Issues, 60, 373-89.

Hall, S. (Ed.). (1997). Cultural representation and signifying practices. London: Sage.

Hall-Cathala, D. (1989). The Israeli peace movement 1967-1987. Oxford: St Anthony/Macmillan.

Hass, A. (1999). Drinking the sea at Gaza. Days and nights in a land under siege. New York: Henry Holt and Company.

Hewstone, M., \& Brown, R. (1986). Contact \& conflict in intergroup encounters. London: Blackwell.

Katriel, T. (1986). Talking straight. Dugri speech in Israeli Sabra culture. Cambridge: Cambridge University Press.

Lave, \& Wenger (1991). Situated learning. Legitimate peripheral participation. Cambrige: Cambridge University Press.

Lovell, T. (2003). Resisting with authority. Theory Culture \& Society, 20(1), 1-17.

Maoz, I. (2000). Multiple conflicts and competing agendas. Peace and Conflict, 6(2), 135-56.

Mayer, C. (1988). The unmasterable past. Cambridge, Mass.: Harvard University Press.

Nelson, K. L., \& Horowitz, L. (2001). Narrative structure in recounted sad memories. Discourse Processes, 31(3), 307-24.

Nir, O. (2002). When Khaled met Niva. Haaretz, 18 February.

Pappé, I. (Ed.). (1999). The Israel/Palestine question. Rewriting histories. London: Routledge.

Pieterse, J. N. (2001). Hybridity, so what? The anti-hybridity backlash and the riddles of recognition. Theory, Culture \& Society, 18(2-3), 219-46.

Rabinowitz, D. (1998). Overlooking Nazareth. Cambridge: Cambridge University Press.

Ricoeur, P. (1983). Time and narrative, vol. 1. Chicago: University of Chicago Press.

Ricoeur, P. (1996). Memory and forgetting. In R. Kearney \& M. Dooley (Eds.), Questioning ethics. London: Routledge.

Rustin, B., \& Clarke, D. (1999). Dealing with conflict. From confrontation to cooperation British friends of Neve Shalom/Wahat al-salam. Session of York, UK: Ebhor Press.

Sagy, S. (2002). Intergroup encounters between Jewish and Arab students in Israel: toward an interactionist approach. Intercultural Education, 13(3), 259-74.

Schwarz, B. (1999). Memories of empire. Presented at Frontiers of Memory conference, University of East London, 18 September.

Silberstein, L. J (1999). Postzionism debates. Knowledge and power in Israeli culture. London: Lawrence \& Wishart.

Vygotsky, L. S. (1962). Thought and language. Cambridge, Mass.: MIT Press. 
Vygotsky, L. S. (1978). Mind in society. London: Sage.

Weiner, E. (Ed.). (1998). Handbook of interethnic coexistence. New York: Continuum.

Willis, P. (1978). Profane culture. London: Routledge \& Kegan Paul.

Yiftachel, O. (1998). Nation-building and the division of space. Nationalism and Ethnic Politics, $4(3), 33-58$.

Zupnik, Y. (2000). Conversational interruptions in Israeli-Palestinian 'dialogue' events. Discourse Studies 2(1), 85-110.

\section{Appendices}

Approximate programme of Face to Face high school encounter, Givat Haviva, October 2001

Day 1:

$9.30-10.00 \quad$ arrival

10.00-11.15 getting to know each other, games

$11.30-11.15$ break

11.30-12.45 personal acquaintance, also cultural acquaintance, boy-girl, family, school, community relations

12.45-15.00 lunch and break

15.00-16.15 deeper cultural acquaintance

$16.15-16.30$ break

$16.30-17.30 \quad$ stereotypes

$17.30-17.45$ break

17.45-19.00 identity issues, personal and group identity

19.00-20.00 dinner

20.00-20.30 preparing cultural presentation

20.30-21.00 cultural performance by each group

21.00 onwards free/leisure time

Day 2:
$8.00-9.00 \quad$ breakfast
9.00-9.45 uni-national session (Jews alone and vice versa), working through yesterday's encounter
9.45-10.00 break
$10.00-11.15$ minority-majority issues
11.15-11.45 letter writing
11.45-12.30 evaluation and processing of what has happened
12.30-13.30 lunch and finish 